\title{
ФОНОЛОГИЯ
}

\author{
Д.Д. Беляев \\ Тульская лаборатория судебной экспертизы МЮ РФ \\ (Россия, Тула) \\ beltula@gmail.com
}

\section{ОТНОШЕНИЯ [Г]-[ช]: ОТ ОППОЗИЦИИ К ВАРЬИРОВАНИЮ}

В статье рассматривается история отношений между звонкими заднеязычными согласными [г] и $[\gamma]$ в русском языке. В ходе славяно-иранского симбиоза $[\gamma]$ стал атрибутом сакральной лексики. Падение редуцированных стимулировало сдвиг к : $\mathbf{\Gamma} \rightarrow \mathbf{\kappa}: \boldsymbol{\gamma}(\boldsymbol{\rightarrow} \mathbf{h})$, поддержанный притяжением в морфонемах $\left\{\mathbf{\Gamma} / \boldsymbol{ж}^{\prime}\right\},\{\mathbf{r} / \mathbf{3}\}$. На юге новые $[\gamma]$ конвергировали с древними, результат был усвоен церковнославянским языком. На севере, где место $\left\{\boldsymbol{\Gamma} / \mathbf{3}^{\prime}\right\}$ заняла морфонема $\left\{\boldsymbol{\Gamma} / \boldsymbol{\Gamma}^{\prime}\right\}$, сдвиг не был обобщен и $[\gamma]$ усваивался как единица книжного языка. Сформировалась внешнелингвистическая оппозиция « $\langle\gamma\rangle$ (книжная речь + Юг) : $\langle\boldsymbol{\Gamma}\rangle$ (разговорная речь $(\mathrm{Ce}-$ вер))». В XVIII в. отношения между $\langle\gamma\rangle$ и $\langle\boldsymbol{\Gamma}\rangle$ подвергаются анализу. В. Е. Адодуров и В.К. Тредиаковский, трактуя фонему $\langle\gamma\rangle$ как немаркированную в $\langle\boldsymbol{\Gamma}\rangle$-ареале, сталкивались с противоречием между нормой и узусом. М.В. Ломоносов, преодолевая противоречие, предложил проект внутренней оппозиции $\langle\boldsymbol{\Gamma}\rangle:\langle\gamma\rangle$, где немаркированной является $\langle\boldsymbol{\Gamma}\rangle$. В XIX в. образовалась мутабельная единица $\langle\boldsymbol{\Gamma} / \gamma\rangle$, варьирующая стилистико-эмоциональную окраску текста. Типологически избыточная оппозиция $\langle\boldsymbol{\Gamma}\rangle:\langle\gamma\rangle$ исчезла. Как показывают идентификационные исследования, в современном русском языке $\langle\Gamma / \gamma\rangle$ является стабильным параметром идиолекта, а также может служить средством создания желаемого коммуникативного образа.

Ключевые слова: русский язык, звонкие заднеязычные согласные, история, мутабельная фонологическая единица, функции

Долгая история отношений между согласными [г] и $[\gamma]$ в русском языке демонстрирует разнообразные факторы - фонологические и экстрафонологические, внутри- и внешнелингвистические.

Спирантизация $\mathbf{g} \rightarrow \boldsymbol{\gamma}$ наблюдается во многих языках [Гамкрелидзе 1980: 97], но реализацию процесса обеспечивают специфические импульсы. Первичный импульс на юго-востоке Славии был, видимо, внешним: славяно-иранский симбиоз 1-й пол. I тыс. н. э., особо значимый для религиозно-мифологической сферы, см. [Васильев 1999; Иванов 1996; Абаев 1965: 41-52, 109-117; Півторак 1988: 128-132; 
Эдельман 2002: 49-53, 157-178]. Фонема $\gamma\rangle$ стала, путем заимствования и семантического калькирования, атрибутом сакральной лексики (богъ [Этимологический словарь славянских языков 2: 157-163] и др.).

Падение редуцированных «привело к резкому повышению напряженности в других звеньях: возникают различные сочетания гетерорганных согласных <..> И дальнейшие фонетические процессы связаны с преодолением этих вновь возникших напряжений» [Касаткин 1999: 139]. В частности, возник внутренний импульс к развитию сдвига $\boldsymbol{\kappa}: \mathbf{\Gamma} \rightarrow \boldsymbol{\kappa}: \boldsymbol{\gamma}(\rightarrow \mathbf{h})$, поддержанного притяжением в морфонемах $\{\boldsymbol{\Gamma} / \boldsymbol{ж}\},\left\{\boldsymbol{\Gamma} / \mathbf{3}^{\prime}\right\}$ [Беляев 1993: 64-69]. На юге падение редуцированных начиналось

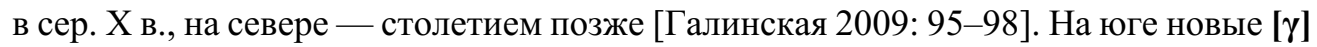
полностью конвергировали с древними. На севере, где место \{r/3'\} заняла морфонема $\left\{\boldsymbol{\Gamma} / \boldsymbol{\Gamma}^{\prime}\right\}$, сдвиг не был обобщен.

Формировавшийся в Киеве церковнославянский язык оперативно воспринял результат сдвига [Успенский 2002: 155-159]. Этому способствовало обучение грамоте по складам [Успенский 2002: 119-121]. Читая слоги, содержащие глаголь, неофиты закономерно артикулировали щелевой согласный. В $\langle\boldsymbol{\Gamma}\rangle$-ареале такое звучание усваивалось как единица книжного языка. Так сформировалась внешнелингвистическая оппозиция « $\langle\gamma\rangle$ (книжная речь + Юг) : $\langle\boldsymbol{\Gamma}\rangle$ (разговорная речь $(\mathrm{Ce}-$ вер))». Ее нейтрализацией на севере стал $[\gamma]$ в сакральных гнездах бог-, блаz-, госnод-. На юго-западе для обозначения иноязычных [г] появились диграф кг (XIV в.) и графема $\boldsymbol{\tau}$ (XVI в.).

В XVII-XVIII вв. отношения между $\langle\gamma\rangle$ и $\langle\boldsymbol{\Gamma}\rangle$ подвергаются анализу и оценке. Выводы внешних наблюдателей категоричны, хотя и противоположны. М. Смотрицкий включает Г в число «странных писмен», «гкш $\mathbf{w}$ Грнкшвъ прнвзАта,

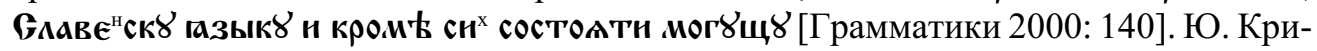
жанич: Р४сјани, МеХи, Хервати, и Өервн, право и рнзво изрнкајЈт слово Гиагол: равно како Греки Гама. А Бнмор४сјани, и ЧеХн, јес४т изгУвнан правнь гмас: и изрнкајУт никако сподовно ко ХирУ. ... Тим се ова४джајУТ и никоьн РУсјанн: и за липо почнтајУТ таково кметско, вА૪Ано, и премерзко изрнканје» [Крижанич 1859: 127].

Русские исследователи XVIII в., трактуя фонему $\langle\gamma\rangle$ как немаркированную, но находясь внутри $\langle\boldsymbol{\Gamma}\rangle$-ареала, неизбежно сталкивались с противоречием между нормой и узусом. Так, В.Е. Адодуров замечает, что «литера $\boldsymbol{t}$ 》 (о неупотреблении

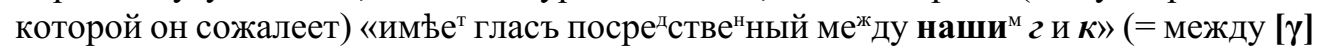
и [к]), и соотносит 2 и $\boldsymbol{x}$ (богъ - бохъ) [Успенский 1975: 94-95, 153-154]. С другой стороны, строя корреляцию по напряженности, он противопоставляет «умяхченные» $\boldsymbol{\sigma}, \boldsymbol{z}, \boldsymbol{d}, \boldsymbol{3}, \boldsymbol{\boldsymbol { c }}$ «жестоким» $\boldsymbol{n}, \boldsymbol{\kappa}, \boldsymbol{m}, \boldsymbol{c}, \boldsymbol{w}$, т. е. соотносит [г] и [к] [Успенский 1975: 98].

В.К. Тредиаковский также соотносит среди «мяхкіх - твердых» $\boldsymbol{z}$ и $\boldsymbol{x}$ [Тредиаковский 1849: 259]. Усомнившись в исконной функции старославянского глаголя, он заключает: «Впрочемъ, сів беsъ всякаго есть спора, что всъ мы россіане нашъ (г) проізносімъ как латінское (h)...» [Тредиаковский 1849: 260]. С другой стороны: «В нашемъ велікороссійскомъ проіsношеніi < .. > нікто у насъ сего сло́ва 
гусь, і бесчісленно многіхъ другіхъ, не проінносітъ $<\ldots>$ какъ чреsъ (h) латінское по немецкому і польскому латіны проізношенію, но какъ чреsъ (g) латінскоЕжъ напрімъръ, gусь...» [Тредиаковский 1849: 261]. Также признавая необходимость графемы Г, он предлагает идеальный проект алфавита со слоговыми названиями: Г [r] — hi, Г [г] - ga [Тредиаковский 1849: 262-269].

М.В. Ломоносов, преодолевая противоречие, выделяет 4 «буквы»: 2 (в благо), $\boldsymbol{x} ; \boldsymbol{z}$ (в глазъ), $\boldsymbol{\kappa}$. Точкой отсчета является отношение $\boldsymbol{z}-\boldsymbol{\kappa}$ : отмечается отсутствие графемы для «латинского $\boldsymbol{h}$ » [Ломоносов 1952: 401-402]. О том же говорят и анализ вариантных чередований «мягких/твердых»: «г - как к или $\boldsymbol{x}$ » (нохти, друкъ, Бохъ); и список функций графемы $2: 1)$ [ү] («осталось от славенского языка»): Бога, Боги...; Господь, гласъ, благо, дериваты государь, государство, господинъ, господствую, разглашаю, благодать, благословляю, благодарю и проч.; 2) [к] в конце слова; 3) [х] в Богъ, в заимствованиях на -ургъ, в лехкой, мяхкой; 4) [в] в род. п. «в простых российских словах и в разговорах», моево, сильнаво; 5) в заимствованиях согласно языку-источнику («нет дальней нужды») [Ломоносов 1952: 426-427]. Чтение [г] принимается по умолчанию.

Таким образом, Ломоносов выдвинул проект внутреннелингвистической оппозиции $\langle\boldsymbol{\Gamma}\rangle:\langle\gamma\rangle$, с немаркированной смычной фонемой. Однако возникала проблема распределения лексики между оппозитами. Ей посвящено стихотворение «О сомнительном произношении буквы Г в российском языке», завершающееся вопросом: «Скажите, где быть га и где стоять глаголю?» [Ломоносов 1959: 580-583]. Вызывает сомнения, что «сам Ломоносов, очевидно, знал ответ на этот вопрос» [Успенский 1994: 210]. Это лишило бы вопрос смысла, см. [Панов 1990: 367-368].

Потому во 2-й пол. XVIII в. преобладает стилистическое нормирование: $[\gamma]$ в высоком стиле - [г] в сниженном [Панов 1990: 297]. А. А. Барсов, описывая «гортанныя буквы», использует 4 символа: $\boldsymbol{\tau} \boldsymbol{t}$ («мягкія») - $\boldsymbol{x} \boldsymbol{\kappa}$ («твердыя») [Российская грамматика 1981: 51]. Однако констатирует: «Одною буквою 2 принуждены мы означать два разные голоса, а именно, соотвътствующіе двумъ латинскимъ буквамъ $\boldsymbol{h}$ и $\boldsymbol{g}$, изъ которыхъ первый < . . > вездъ безъ изъятія въ славенскихъ словахъ и въ чтеніи книгъ, особливо церковныхъ, выговаривается; на противъ того другой несравненно болъе употребителенъ въ обыкновенныхъ разговорахъ и собственно въ россійскомъ языкъ...» И строит свой список церковнославянских включений [Российская 1981: 43].

Подобные списки появлялись и в ХІХ в. [Панов 1990: 97-99, 200-201]. Но параллельно происходило главное: в литературном языке формировалась мутабельная фонематическая единица, «которая объединяет две фонемы, свободно варьирующиеся в одной позиции, так что обе вариации принадлежат одному и тому же слову» [Панов 1990: 192]. Это позволяло «варьировать стилистико-эмоциональную окрашенность текста» [Панов 1990: 193], но препятствовало выполнению различительной функции.

Постепенно лексико-стилистическая сфера $\langle\gamma>$ сужалась. В XX в. она утратила нормативный статус даже в своей исконной сфере - церковно-богословской речи [Успенский 2002: 159].

Так проявилась типологическая закономерность: «При наличии в системе маркированных смычных $/ \mathbf{p} /$ и $/ \mathbf{g} /<\ldots>$ присутствие $<\ldots>$ соответствующих фрикативных 
фонем /f/ и / $\gamma /$ факультативно [Гамкрелидзе 1980: 96]. Для фонемы 〈ф〉системный контекст оказался более благоприятным, и избыточность консонантизма была уменьшена только за счет оппозиции $\langle\Gamma\rangle:\langle\gamma\rangle$.

Однако снятие фонологической оппозиции не равно фонетической унификации. «В языке, как и вообще в природе, ничто не возникает из ничего и ничто не исчезает бесследно» [Журавлев 1986: 188]. Для рассмотрения судьбы мутабельной единицы $\left\langle\boldsymbol{\Gamma}^{(9)} / \gamma^{(9)}\right\rangle$ были использованы идентификационные исследования 2003-2017 гг., проведенные в Тульской ЛСЭ Минюста России. Среди исходных и сравнительных текстов есть диалогические и монологические, спонтанные и читаемые, бытовые и официальные.

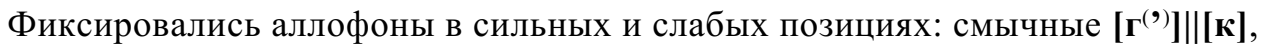
щелевые $\left[\boldsymbol{\gamma}^{(\boldsymbol{)})} / \mathbf{h}^{(\boldsymbol{)})}\right]||[\mathbf{x}]$. Все фонограммы, содержащие более 10 примеров, оказа-

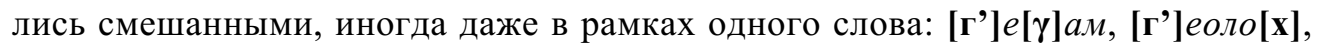

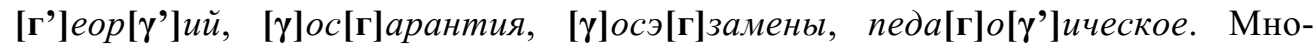
жество аллофонов (15316) разбивается практически поровну $(\boldsymbol{\Gamma}=\mathbf{5 0 , 7} \% ; \gamma=$ $49,3 \%$ ).

Вариантам не присущи ни лексическая закрепленность, ни позиционная обусловленность. Будучи свободными, они образуют фонемы $\langle\boldsymbol{\Gamma} / \boldsymbol{\gamma}\rangle,\left\langle\boldsymbol{\Gamma}^{\prime} / \gamma^{\prime}\right\rangle$, лишенные ДП способа образования. В варьировании участвуют и гиперфонема $\langle\mathrm{r} / \mathrm{k}\rangle$ (2де, когда, тогда, вокзал, экзамен), и фонема $\langle\mathbf{\kappa}\rangle$ (как бы, как же, и так далее, так

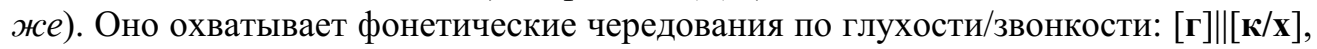
$[\gamma]|[\mathbf{x} / \mathbf{\kappa}],[\mathbf{\kappa}]| \mid[\mathbf{r} / \gamma]$.

Из 80 дикторов у 45 преобладают щелевые согласные, у 35 - смычные. Однако смычные варианты доминируют во внешнелингвистическом пространстве. Официальный характер сравнительного образца (открыто фиксируемое следственное действие) чаще всего стимулирует повышение их доли:

\begin{tabular}{|c|c|c|c|c|}
\hline \multicolumn{3}{|c|}{ Официальные образцы (62) } & \multicolumn{2}{c|}{ Неофициальные образцы (18) } \\
\hline$\Gamma>(49)$ & $\Gamma<(11)$ & $\Gamma=(2)$ & $\Gamma>(7)$ & $\Gamma<(11)$ \\
\hline
\end{tabular}

О том же говорит большее региональное разнообразие идиолектов с их преобладанием (для 18 дикторов данные отсутствуют):

\begin{tabular}{|c|c|l|}
\hline $\boldsymbol{\Gamma}$ & $\mathbf{1 3}(\mathbf{2 8 )})$ & $\begin{array}{l}\text { Тула (15), Москва (2), Баку, Гомель, Калуга, Краснодар, Крым, } \\
\text { Магадан, Минск, Одесса, Псков, Самара, Черкассы }\end{array}$ \\
\hline$\gamma / \mathbf{h}$ & $\mathbf{5}(\mathbf{3 4})$ & $\gamma$ : Тула (29), Владивосток (2), Рязань; $\mathbf{h}$ : Брянск, Смоленск \\
\hline
\end{tabular}

Доли преобладающего типа аллофонов составляют от $\mathbf{5 0 , 0}$ до 97,7\%. Относительное отклонение ОО между долями в исходных записях и образцах (отношение модуля их разности к среднему значению доли) в 74 случаях находится в пределах 0-7\% (см. диаграмму на с. 180).

Аномально высокие (более $10 \%$ ) значения ОО вызваны особыми причинами.

1. Преднамеренная смена коммуникативного образа (рост доли г; особенно наглядны случаи внутридикторской дифференциации материала: $1.5,1.6)$. 


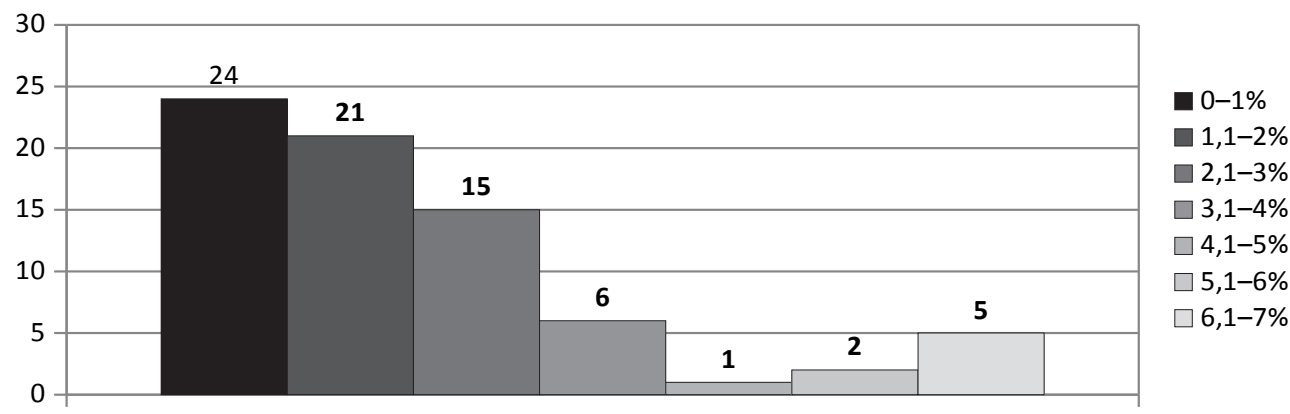

1.1. Журналист БСС. Посредник в вымогательстве. Исходный материал — диалоги с сообщником и с объектом вымогательства $(\boldsymbol{r}=\mathbf{7 4 , 8 \%})$. В официальном образце строит образ эффективного менеджера $(\mathbf{r}=\mathbf{8 3 , 7 \%}, \mathrm{OO}=\mathbf{1 1 , 2} \%)$.

1.2. Сотрудник милиции БРВ. Исходный материал - переговоры о фабрикации уголовного дела $(\gamma=\mathbf{6 3 , 8} \%)$. В официальном образце строит образ интеллектуала, знатока древней истории $(\gamma=\mathbf{5 6 , 2} \%, \mathrm{OO}=\mathbf{1 2 , 7 \%})$.

1.3. Телефонный мошенник СМК. Образец - неофициальная беседа с работником СИЗО $(\gamma=\mathbf{5 9 , 4} \%)$. В исходном разговоре играет роль менеджера автосалона $(\gamma=\mathbf{5 1 , 1} \%, O O=\mathbf{1 5 , 0} \%)$.

1.4. Бизнесмен, депутат областной думы ФСМ. Исходный материал - диалог с партнером по бизнесу $(\gamma=\mathbf{9 6 , 9} \%)$. В официальном образце строит образ респектабельного политика $(\gamma=\mathbf{7 7 , 2} \%, 0 O=22,6 \%)$.

1.5. Телефонный мошенник КСВ. Играет роль следователя. Диалоги с сообщником $(\boldsymbol{\Gamma}=\mathbf{6 0 , 7} \%)$ близки к официальному образцу $(\boldsymbol{\Gamma}=\mathbf{6 2 , 5 \%}, 00=\mathbf{2 , 9 \%})$. Диалоги с жертвой обмана далеки от него $(\boldsymbol{\Gamma}=\mathbf{8 6 , 9 \%}, \mathrm{OO}=\mathbf{3 2 , 7 \%})$.

1.6. Телефонный мошенник ИДА. Виртуозно играет роль менеджера автосалона. В диалогах с сообщниками преобладают щелевые варианты $(\gamma=\mathbf{6 8 , 0} \%)$, доля которых идентична образцу - неофициальной беседе с работником СИЗО ( $\gamma=$ $67,8 \%, 00=0,3 \%)$. В диалогах с жертвами обмана, напротив, господствуют варианты смычные $(\boldsymbol{\Gamma}=\mathbf{9 5 , 8} \%$, OO $=\mathbf{9 9 , 4} \%$ !).

2. Вынужденная смена психофизического состояния (двойственный эффект).

2.1. Наркодилер ТРФ. Исходный материал - диалоги с сообщниками $(\gamma=$ $\mathbf{6 6 , 7} \%$ ). В официальном образце конфликт с работниками СИЗО породил эмоциональное и артикуляционное напряжение, снизившее долю щелевых вариантов ( $\gamma=$ $60,0 \%, O O=10,6 \%)$

2.2. Офицер ГМВ. Исходный материал - диалоги с сослуживцами о плате за должность $(\boldsymbol{\Gamma}=\mathbf{8 1 , 5 \%})$. Официальный образец - чтение текста «Антоныч», вызвавшее большие затруднения. Артикуляционное напряжение повысило долю смычных вариантов $(\boldsymbol{\Gamma}=\mathbf{9 0 , 4} \%, 00=\mathbf{1 0 , 3} \%)$.

2.3. Адвокат ЛОА. Посредница в вымогательстве. Обычные диалоги $(\boldsymbol{\Gamma}=$ $\mathbf{9 2 , 1 \%}$ ) близки к официальному образцу $(\boldsymbol{r}=\mathbf{9 0 , 3} \%, \mathbf{O O}=\mathbf{2 , 0} \%)$. Однако в разговоре, сопровождающемся приемом алкоголя, артикуляция становится вялой, доля смычных резко убывает $(\Gamma=67,9 \%, 00=28,3 \%)$. 
Итак, проведенный анализ показывает, что:

1. В современном русском языке мутабельная единица $\left\langle\boldsymbol{\Gamma}^{\left({ }^{(}\right)} / \boldsymbol{\gamma}^{\left({ }^{()}\right.}\right\rangle$является стабильным параметром идиолекта.

2. На этом фоне она служит средством создания желаемого коммуникативного образа.

\section{Литература}

Абаев В. И. Скифо-европейские изоглоссы. М.: Наука, 1965. 168 с.

Беляев Д.Д. Славянские задненебные после падения редуцированных // Вопросы языкознания. 1993. №6. С. 64-77.

Васильев М.А. Язычество восточных славян накануне крещения Руси. М.: Индрик, 1999. $328 \mathrm{c.}$

Галинская Е. А. Историческая фонетика русского языка. М.: Изд-во МГУ, 2009. $160 \mathrm{c}$.

Гамкрелидзе Т.В. Маркированность в фонологии и типология фонологических систем // Теоретические основы классификации языков мира. М.: Наука, 1980. C. 62-99.

Грамматики Лаврентия Зизания и Мелетия Смотрицкого. М.: Изд-во МГУ, 2000. $526 \mathrm{c}$.

Журавлев В. К. Диахроническая фонология. М.: Наука, 1986. 232 с.

Иванов Вяч. Вс. Славяно-(восточно)иранские сходства. Дополнительные сближения // Славянские языки в зеркале неславянского окружения. Тез. междунар. конф. М.: Ин-т славяноведения и балканистики РАН, 1996. С. 26-31.

Касаткин Л. Л. Современная русская диалектная и литературная фонетика как источник для истории русского языка. М.: Наука, 1999. 526 с.

Крижанич Ю. Граматично изказанје об руском језику... М.: Унив. тип., 1859. $\mathrm{XX}+\mathrm{VI}+256 \mathrm{c}$.

Ломоносов М. . Полн. собр. соч. М.; Л.: Изд-во АН СССР, 1952. Т. 7. 997 с.; 1959. T. 8. $1288 \mathrm{c}$.

Панов М.В. История русского литературного произношения XVIII-XX вв. М.: Наука, 1990. 456 с.

Півторак Г.П. Формування і діалектна диференціація давньоруської мови. Київ: Наукова думка, 1988. 280 с.

«Российская грамматика» А. А. Барсова. М.: Изд-во МГУ, 1981. 776 с.

Тредиаковский B.K. Разговор между чужестранным человеком и российским об ортографии старинной и новой... // Тредиаковский В.К. Сочинения. СПб.: А. Смирдин, 1849. Т. 3. С. I-IV + 1-316 c.

Успенский Б. А. Первая русская грамматика на родном языке. М.: Наука, 1975. $232 \mathrm{c}$.

Успенский Б.А. Фонетическая структура одного стихотворения Ломоносова // Успенский Б.А. Избранные труды. М.: Гнозис, 1994. Т. 2. С. 207-241. 
Успенский Б.А. История русского литературного языка (XI-XVII вв.). М.: Аспект Пресс, 2002. 558 с.

Эдельман Д.И. Иранские и славянские языки: Исторические отношения. М.: Вост. лит-ра, 2002. 230 с.

Этимологический словарь славянских языков. М.: Наука, 1974-. Вып. 1-.

\author{
Dmitry D. Belyaev \\ Tula laboratory of judicial examination \\ of the Ministry of Justice of the Russian Federation \\ (Russia, Tula) \\ beltula@gmail.com
}

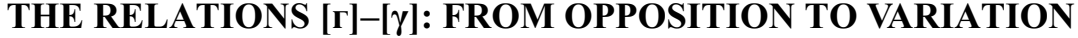

This paper is devoted to the history of the relations between voiced velar consonants $[\boldsymbol{\Gamma}]$ and $[\gamma]$ in Russian. During the Slavic-Iranian symbiosis $[\gamma]$ became attribute of sacral lexicon. The fall of the jers stimulated shift $\mathbf{\kappa}: \mathbf{\Gamma} \rightarrow \mathbf{K}: \boldsymbol{\gamma}(\rightarrow \mathbf{h})$, supported by an attraction in morphonemes $\left\{\mathbf{\Gamma} / \boldsymbol{\Psi}^{\prime}\right\},\{\mathbf{\Gamma} / \mathbf{3}\}$. In the South new $[\gamma]$ converged with ancient, the result has been acquired by Church Slavonic. In the North, where the place of $\left\{\mathbf{r} / \mathbf{3}^{\prime}\right\}$ was occupied by a morphoneme $\left\{\boldsymbol{\Gamma} / \boldsymbol{\Gamma}^{\prime}\right\}$, the shift hasn't been generalized, and $[\gamma]$ was acquired as unit of literary language. The supralinguistic opposition " $\langle\gamma\rangle$ (bookish speech + South) : [г] (colloquial speech North)" was formed. In the $18^{\text {th }}$ century the relations between $[\gamma]$ and $[\boldsymbol{\Gamma}]$ were exposed to the analysis. V.E. Adodurov and V.K. Trediakovskii, treating $\langle\gamma\rangle$ as unmarked phoneme in a $\langle\boldsymbol{\Gamma}\rangle$-area, faced a contradiction between norm and usage. M. V. Lomonosov, trying to overcome this contradiction, offered the project of internal opposition $\langle\boldsymbol{\Gamma}\rangle:\langle\gamma\rangle$, where $\langle\boldsymbol{\Gamma}\rangle$ is unmarked. In the $19^{\text {th }}$ century the mutable unit $\langle\boldsymbol{\Gamma} / \gamma\rangle$ was created, which varied stylistic and emotional coloring of the text. Typologically excessive opposition $\langle\boldsymbol{\Gamma}\rangle:\langle\gamma\rangle$ disappeared. As identification researches show, in modern Russian $\langle\mathbf{r} / \gamma\rangle$ is the stable parameter of an idiolect and can also serve as a tool for a desirable communicative image.

Key words: Russian language, voiced velar consonants, history, mutable phonological unit, functions

\section{References}

Abaev V.I. Skifo-evropeiskie izoglossy [Scythian-European isoglosses]. Moscow, Nauka Publ., 1965. 168 p.

Belyaev D.D. [Slavic velars after fall of the jers]. Voprosy yazykoznaniya. 1993. No. 6. P. 64-77. (In Russ.)

Edel'man D. I. Iranskie i slavyanskie yazyki: Istoricheskie otnosheniya [Iranian and Slavic languages: Historical relations]. Moscow, Vostochnaya literatura Publ., 2002. $230 \mathrm{p}$. 
Etimologicheskii slovar' slavyanskikh yazykov [Etymological dictionary of Slavic languages]. Moscow, Nauka Publ., 1974-. Vol. 1-.

Galinskaya E. A. Istoricheskaya fonetika russkogo yazyka [Historical phonetics of Russian]. Moscow, Moscow St. Univ. Publ., 2009. 160 p.

Gamkrelidze T. V. [Markedness in phonology and typology of phonological systems]. Teoreticheskie osnovy klassifikatsii yazykov mira [Theoretical bases of classification of languages of the world]. Moscow, Nauka Publ., 1980. P. 62-99. (In Russ.)

Grammatiki Lavrentiya Zizaniya i Meletiya Smotritskogo [Grammars of Lavrentii Zizanii and Meletii Smotritskii]. Moscow, Moscow St. Univ. Publ., 2000. 528 p.

Ivanov Vyach. Vs. [Slavic-(East)Iranian similarities. Additional rapprochements]. Slavyanskie yazyki v zerkale neslavyanskogo okruzheniya. Tez. mezhdunar. konf. [Slavic languages in a mirror of a non-Slavic environment. Theses of the int. conf.]. Moscow, Inst. of Slavic and Balkan Studies of RAS, 1996. P. 26-31. (In Russ.)

Kasatkin L. L. Sovremennaya russkaya i dialektnaya fonetika kak istochnik dlya istorii russkogo yazyka [Modern Russian dialect and literary phonetics as a source for history of the Russian language]. Moscow, Nauka Publ., 1999. 526 p.

Krizhanich Yu. Gramatichno izkazan'e ob ruskom eziku... [Grammatical Instruction on the Russian Language]. Moscow, Univ. Print., 1859. XX + VI + 256 p.

Lomonosov M.V. Polnoe sobranie sochinenii [Complete works]. Moscow; Leningrad, USSR Acad. of Sciences Publ., 1952. Vol. 7. 997 p.; 1959. Vol. 8. 1288 p.

Panov M. V. Istoriya russkogo literaturnogo proiznosheniya XVIII-XX vv. [History of the Russian literary pronunciation of the $18^{\text {th }}-20^{\text {th }}$ centuries]. Moscow, Nauka Publ., 1990. $456 \mathrm{p}$.

Pivtorak G.P. Formuvannya i dialektna diferentsiatsiya davn'orus'koi movi [The formation and differentiation of the dialect of the Old Russian]. Kiev, Naukova dumka Publ., 1988. 280 p. (In Ukr.)

"Rossiiskaya grammatika" A.A. Barsova ["Russian Grammar" of A. A. Barsov]. Moscow, Moscow St. Univ. Publ., 1981. 776 p.

Trediakovskii V.K. [Conversation between the foreign person and Russian about an orthography ancient and new...] Trediakovskii V.K. Sochineniya [Trediakovskii V.K. Works]. St. Petersburg, A. Smirdin Publ., 1849. Vol. 3. P. I-IV + 1-316. (In Russ.)

Uspenskii B. A. Pervaya russkaya grammatika na rodnom yazyke [The first Russian grammar in the native language]. Moscow, Nauka Publ., 1975. 232 p.

Uspenskii B. A. [Phonetic structure of one poem of Lomonosov] Uspenskii B. A. Izbrannye trudy [Uspenskii B. A. Chosen works]. Moscow, Gnosis Publ., 1994. Vol. 2. P. 207-241. (In Russ.)

Uspenskii B. A. Istoriya russkogo literaturnogo yazyka (XI-XVII vv.) [History of the Russian literary language (the $11^{\text {th }}-17^{\text {th }}$ centuries)]. Moscow, Aspekt Press Publ., 2002. 558 p.

Vasil'ev M. A. Yazychestvo vostochnykh slavyan nakanune kreshcheniya Rusi [Paganism of East Slavs on the eve of the Christianization of Kievan Rus']. Moscow, Indrik Publ., 1999. 328 p.

Zhuravlev V.K. Diakhronicheskaya fonologiya [Diachronic phonology]. Moscow, Nauka Publ., 1986. 232 p. 